\title{
Plateau stress estimation of impact compression test on aluminum foam using $X$-ray computed tomography observation
}

\author{
Takao UTSUNOMIYA*, Yoshihiko HANGAI**, Naoyuki KUBOTA***, \\ Osamu KUWAZURU $* * * *$ and Nobuhiro YOSHIKAWA***** \\ *Department of Mechanical Engineering, Shibaura Institute of Technology, \\ 3-7-5 Toyosu, Koto-ku, Tokyo 135-8548, Japan \\ E-mail: utunomiy@sic.shibaura-it.ac.jp \\ ${ }^{* *}$ Graduate School of Science and Technology, Gunma University, \\ 1-5-1 Tennjin-cho, Kiryuu, Gunma 376-8515, Japan \\ ${ }^{* * *}$ Graduate Student, Gunma University, \\ 1-5-1 Tennjin-cho, Kiryuu, Gunma 376-8515, Japan \\ **** Graduate School of Engineering, University of Fukui, \\ 3-9-1 Bunkyo, Fukui, Fukui 910-8507, Japan \\ ***** Institute of Industrial Science, The University of Tokyo, \\ 4-6-1 Komaba, Meguro-ku,Tokyo 153-8505, Japan
}

\section{Received 1 March 2016}

\begin{abstract}
The plateau stress of aluminum ( $\mathrm{Al})$ foam is an important mechanical parameter that is closely related to its energy absorptivity. An estimation method for plateau stress was proposed by simply assuming that when the mean true compressive stress on a maximum-porosity cross section perpendicular to the direction of compressive loading reaches the critical value, the nominal compressive stress becomes equal to the plateau stress. In this study, using commercial-purity A1050 Al, A6061 Al alloy and ADC12 Al alloy die castings containing a large amount of gases, uniform $\mathrm{Al}$ foam and two types of functionally graded (FG) $\mathrm{Al}$ foam were fabricated by the friction stir welding (FSW) route precursor process. The local porosity distributions for the fabricated $\mathrm{Al}$ foams were obtained from the observation of X-ray computed tomography (CT) images, then drop weight impact tests were carried out to evaluate the plateau stresses. Through the comparison of the test results with the results obtained by the estimation method, the applicability of the estimation method for plateau stress to impact compression tests on uniform aluminum $\mathrm{Al}$ foam and each foam layer of $\mathrm{FG} \mathrm{Al}$ foam was examined. It was shown that the plateau stresses can be evaluated approximately within $\pm 20 \%$ error when the proof stress is employed as the critical value.
\end{abstract}

Key words : Porous material, Friction joint, Ductile fracture, Material testing, Plateau stress, Compression test, Porosity

\section{Introduction}

Aluminum (Al) foam is very lightweight and has excellent energy absorptivity. Because of these superior properties, $\mathrm{Al}$ foam is expected to be applied as a multifunctional material in various industrial fields (Banhart, 2005, Banhart and Seeliger, 2012). Uniform Al foam can exhibit various properties depending on its base material and pore structure (i.e., porosity and pore size) (Gibson, 2000). In recent years, to improve the performance of $\mathrm{Al}$ foam, functionally graded (FG) aluminum foams, which consist of foam layers with different material compositions and pore structures, have been developed (Brothers and Dunand, 2008, Hangai et al., 2012a, Hangai et al., 2013, Hassani et al., 2012, Shinagawa, 2008, Suzuki and Kitazono, 2008). One of the major fabrication processes of uniform and FG Al foams is the precursor foaming process (Banhart and Seeliger, 2012, Banhart, 2013). The authors proposed the precursor 
foaming process utilizing the friction stir welding (FSW) route, called the FSW route precursor foaming process (Hangai et al., 2009, Hangai et al., 2010) and succeeded in fabricating uniform Al foams with various base materials and FG Al foams consisting of several foam layers with different pore structures and alloy compositions (Hangai et al., 2012a, Utsunomiya et al., 2010a, Utsunomiya et al., 2011). Moreover, to consider the applications of uniform and FG Al foams as shock absorbers of vehicles, the compressive behaviors of these foams have been studied through static and impact compression tests (Utsunomiya et al., 2010b, Utsunomiya et al., 2014, Hangai et al., 2014, Hangai et al., 2015).

As a characteristic of the compression stress-strain curve obtained by a compression test on Al foam, a plateau region with an approximately constant stress up to a large strain appears. The plateau stress is defined as the average stress for the range of strain of 0.2-0.3 in the plateau region (Japanese Standards Association, 2008, 2012). Therefore, it can be considered that the plateau stress is closely related to the amount of energy absorption evaluated for the range of strain of 0-0.5 in the plateau region (Japanese Standards Association, 2008, 2012). In a previous study, we proposed a simple estimation method for the plateau stress based on the mean true compressive stress on a maximum-porosity cross section perpendicular to the direction of compressive loading, considering that a locally deformed layer is formed in the plateau region and that the porosity greatly affects the plateau stress (Utsunomiya et al., 2013). Moreover, through the comparison between results obtained by the proposed simple estimation method and static compression test results for ADC12 and A1050 uniform Al foams, it was shown that the plateau stress can be estimated by the simple estimation method (Utsunomiya et al., 2013).

In this study, we fabricated three uniform Al foams of commercial-purity A1050 Al, A6061 Al-Mg-Si Al alloy and ADC12 Al-Si-Cu Al alloy die castings (equivalent to A383.0 Al alloy), and two types of FG Al foam with combinations of A6061/A1050 and ADC12/A1050. Next, through the nondestructive observation of the fabricated uniform and FG Al foams by X-ray computed tomography (CT), distributions of the porosity on cross sections perpendicular to the direction of compression loading were obtained. Also, elemental $\mathrm{Mg}$, which only exists in the A6061 Al alloy, was observed by electron probe microanalysis (EPMA) to determine the boundary between the two layers of the A6061/A1050 FG Al foam. Moreover, drop weight impact compression tests and static compression tests were carried out on the uniform and FG Al foams to evaluate the plateau stresses. The simple estimation method for the plateau stress was applied to estimate the plateau stresses for the uniform Al foams and each layer of the FG Al foams. Similar uniform and FG Al foams to those fabricated in this study have already been fabricated in previous studies (Utsunomiya et al., 2014, Hangai et al., 2014, Hangai et al., 2015); therefore, the results obtained in the previous studies are also contained in the estimation carried out in this study. Through the comparison of the compression test results with the estimated results, the possibility of estimating plateau stresses by the simple estimation method is discussed for the uniform $\mathrm{Al}$ foams and each layer of the FG Al foams.

\section{Fabrication of Al foams and compression test specimens 2.1 Uniform Al foams}

Uniform Al foams were fabricated using commercial-purity A1050 Al, A6061 Al-Mg-Si Al alloy and ADC12 $\mathrm{Al}-\mathrm{Si}-\mathrm{Cu} \mathrm{Al}$ alloy die castings (equivalent to A383.0 Al alloy). Figure 1 shows a schematic illustration of the process used to fabricate uniform Al foams by the FSW route precursor foaming method (Hangai et al., 2009, Hangai et al., 2010). Two Al plates, $\mathrm{A}$ and $\mathrm{B}$, of $3 \mathrm{~mm}$ thickness and $80 \mathrm{~mm}$ width were stacked with agent powders distributed between them (cf. Fig. 1(a)). A blowing agent powder $\left(\mathrm{TiH}_{2},<45 \mu \mathrm{m}\right)$ and a stabilization agent powder $\left(\alpha-\mathrm{Al}_{2} \mathrm{O}_{3}, \sim 1 \mu \mathrm{m}\right)$ were both used for the A1050 and A6061 plates, and only stabilization agent powder was used for the ADC12 plate. As shown in Fig. 1(b), the probe of a rotating tool was inserted into plates A and B, and multipass FSW was applied to obtain a larger precursor and to mix the gases and powders thoroughly using an FSW machine (SHH204-720, Hitachi Setsubi Engineering Co., Ltd.). In the multipass FSW, 5 lines $\times 4$ passes for A6061 and ADC12 plates and 5 lines $\times 2$ passes for A1050 plate were used. Moreover, as shown in Fig. 1(c), after the plates joined by FSW were turned over, the agent powders were placed on the reverse side of the FSW surface and Al plate C was stacked on the joined plates. Then, as shown in Fig. 1(d), the same FSW procedure was carried out to obtain a thick precursor. Here, the amounts of $\mathrm{TiH}_{2}$ relative to the mass of the plate with the volume stirred by FSW were 1 mass $\%$ and 0.6 mass $\%$ for the A1050 and A6061 plates, respectively. The ADC12 plate potentially contained some gases. These gases were used to fabricate Al foam without using a blowing agent (Hangai et al., 2012b, Utsunomiya et al., 2011). The amount of $\mathrm{Al}_{2} \mathrm{O}_{3}$ powder was 5 mass $\%$ relative to the mass of the plate with the above stirred volume for all the plates. The tool rotation speed and 
welding speed were $2200 \mathrm{rpm}$ and $100 \mathrm{~mm} / \mathrm{min}$ for the A1050 plate and $1000 \mathrm{rpm}$ and $100 \mathrm{~mm} / \mathrm{min}$ for the A6061 and ADC12 plates, respectively. A tilt angle of $3^{\circ}$ was used throughout the fabrication. Foamable precursors were machined from the stirred region (cf. Fig. 1(e)). The foamable precursors were heated in a preheated electric furnace with a holding temperature and holding time of $1003 \mathrm{~K}$ and 12-13 min for the A1050 Al foam and $1003 \mathrm{~K}$ and $11.5-12 \mathrm{~min}$ for the A6061 Al foam, respectively. Those for the ADC12 Al foam were 10-12 min at $948 \mathrm{~K}, 10.5 \mathrm{~min}$ at $973 \mathrm{~K}$ and 8.5-10.5 min at $1003 \mathrm{~K}$. The foamed samples were cut by electro-discharge machining to obtain compression test specimens with dimensions of $25 \mathrm{~mm} \times 25 \mathrm{~mm} \times 25 \mathrm{~mm}$ for the A1050 and A6061 Al foams and dimensions of 20 $\mathrm{mm} \times 20 \mathrm{~mm} \times 20 \mathrm{~mm}$ for the ADC12 Al foam (cf. Fig. 1(f)). As an example of a compressive test specimen, Fig. 2 shows the uniform A6061 Al foam specimen.

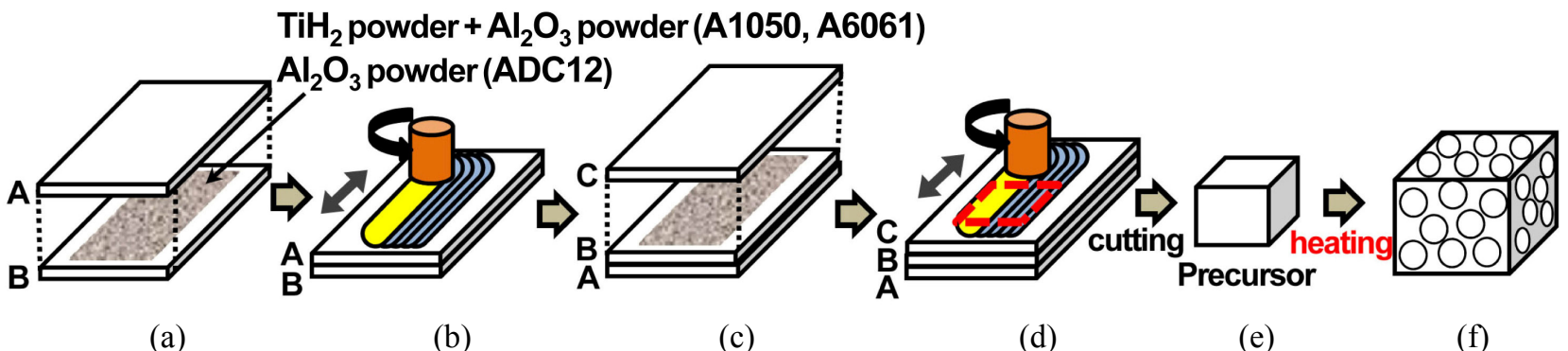

Fig. 1 Schematic illustration of fabrication process used for uniform aluminum foams by friction stir welding (FSW) route precursor foaming process. (a) The powders were placed along the path of the FSW tool. (b) FSW was carried out. (c) The plates were turned over and the powders were placed along the path of the FSW tool. (d) FSW was carried out again. (e) The precursor was cut. (f) The precursor was heated and a specimen was cut from the foam sample.

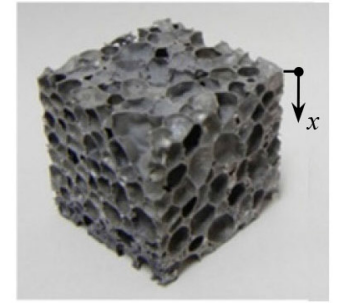

$10 \underline{\mathrm{mm}}$

Fig. 2 Uniform Al foam specimen (A6061).

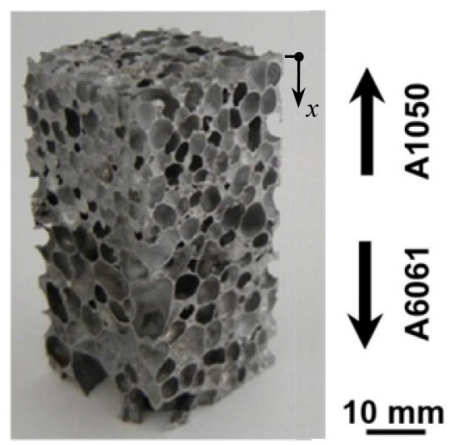

Fig. 4 FG Al foam specimen (A6061/A1050).

\subsection{FG Al foams}

Figure 3 shows a schematic illustration of the process of fabricating an FG Al foam precursor (Hangai et al., 2012a, Hangai et al., 2014, Hangai et al., 2015, Utsunomiya et al., 2010b). As shown in Figs. 3(a)-(d) and Figs. 3(a')-(d'), the stirred A1050, A6061 and ADC12 Al plates were fabricated by the same FSW route as the uniform Al foams described in the previous subsection and were then cut in the stirred region. Two stirred plates with combinations of A6061/A1050 and ADC12/A1050 were butt-welded by FSW, as shown in Fig. 3(e). 1 line $\times 1$ pass FSW was applied along the bonding line. The tool rotation speed and welding speed were $1000 \mathrm{rpm}$ and $100 \mathrm{~mm} / \mathrm{min}$, respectively. The precursor samples were machined from the stirred region including the welding line, as shown by the dashed lines in Fig. 3(e). The obtained precursors (cf. Fig. 3(f)) were heated in a preheated electric furnace with the holding temperature and holding time set at $1003 \mathrm{~K}$ and $12.5-15 \mathrm{~min}$ for the A6061/A1050 FG Al foam, and $1003 \mathrm{~K}$ and 10.5-13 min for the ADC12/A1050 FG Al foam to fabricate FG Al foams with almost the same porosity as the uniform Al foams, respectively. A compression test specimen of $20 \mathrm{~mm} \times 20 \mathrm{~mm} \times 40 \mathrm{~mm}$ was obtained from each foamed sample by electro discharge machining (cf. Fig. 3(g)). As an example of a compressive test specimen, Fig. 4 shows the A6061/A1050 FG Al foam specimen. 


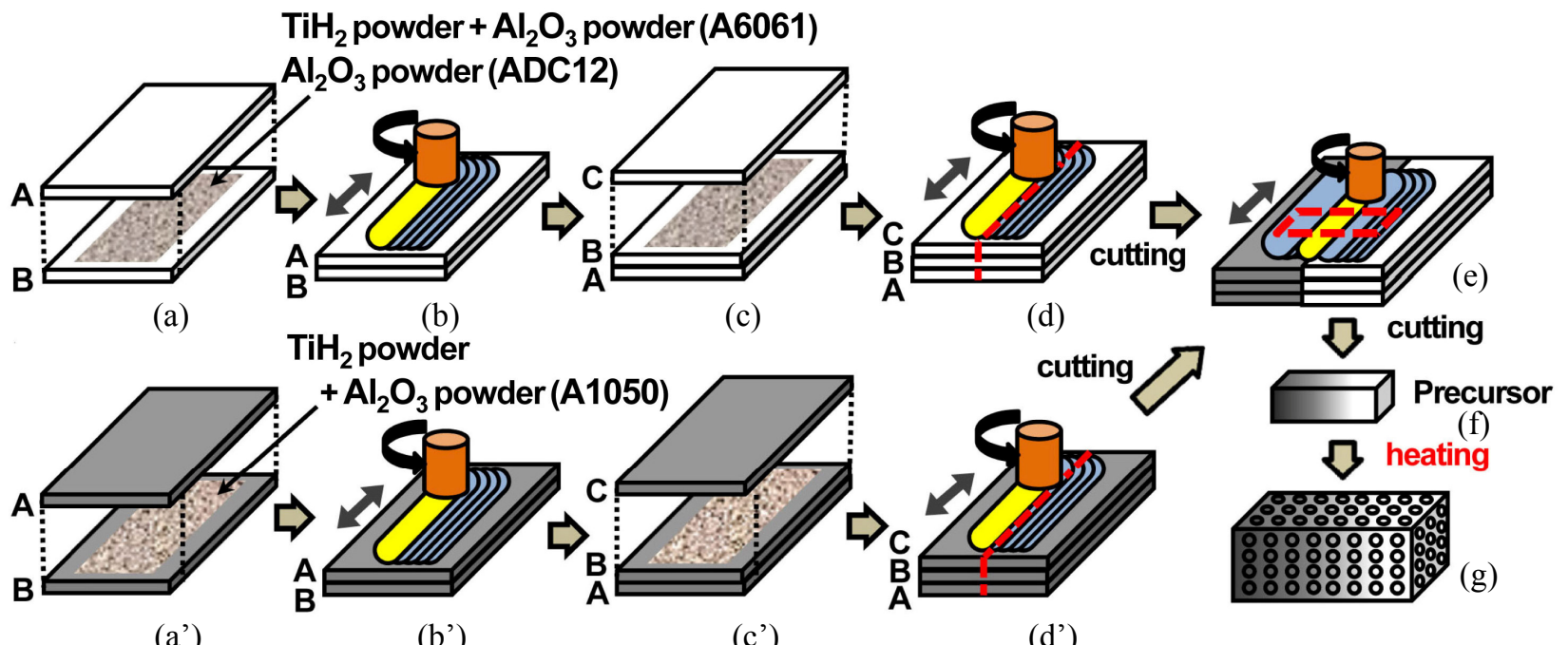

(a')

(b')

(c')

(d')

Fig. 3 Schematic illustration of fabrication process used for FG aluminum foams by FSW route precursor foaming process. (a), (a') The powders were placed along the path of the FSW tool. (b), (b') FSW was carried out. (c), (c') The plates were turned over and the powders were placed along the path of the FSW tool. (d), (d') FSW was carried out and the laminated plate was cut in the stirred region. (e) The cut plates were butt-welded by FSW. (f) The precursor was cut. (g) The precursor was foamed and a specimen was cut from the foam sample.

\section{Observations of compression test specimens 3.1 X-ray computed CT observation}

The overall porosity $p$ of each compression test specimen was evaluated from the measured weight and dimensions. Each specimen was scanned using a microfocus X-ray CT system (SMX-225CT, Shimadzu Corporation). The X-ray source was tungsten and a cone-type CT system was employed. This system can obtain a set of two-dimensional cross-sectional X-ray CT images of a specimen with a slice pitch equal to the length of one pixel by a single rotation of the specimen. The X-ray tube voltage and current used in the inspection were $80 \mathrm{kV}$ and $30 \mu \mathrm{A}$, respectively. The resolution of each X-ray CT image was $512 \times 512$ pixels. The lengths per pixel were approximately $76 \mu \mathrm{m}$ for the A1050 and A6061 uniform Al foam specimens, $58 \mu \mathrm{m}$ for the ADC12 specimen and $90 \mu \mathrm{m}$ for the A6061/A1050 and ADC12/A1050 FG Al foam specimens.

In this study, a threshold was set for all the X-ray CT images to distinguish the cell walls and the pores clearly and to construct binarized X-ray CT images. From the obtained binarized images, the distribution of the local porosity $p_{x}$ on the cross sections of the specimen perpendicular to the direction of compressive loading was evaluated, so that the average value of $p_{x}$ for the entire specimen became equal to the value of $p$ for the specimen evaluated using its weight and dimensions. Moreover, the equivalent diameter $d$ was evaluated by the following equation:

$$
d=2\left(\frac{A}{\pi}\right)^{\frac{1}{2}}
$$

where $A$ is the area of each pore. Here, pores with area less than $1.0 \mathrm{~mm}^{2}$ were excluded owing to the resolution of the $\mathrm{X}$-ray CT images. From the average values of $d$ for all pores in each specimen, the average equivalent diameter $d_{\mathrm{m}}$ was calculated. In these evaluations, image-processing software (WinROOF, Mitani Corporation) was used.

The values of $p$ for the A1050, A6061 and ADC12 uniform Al foam specimens were 83-91\%, 79-90\% and 74-83\%, respectively. Those for the A6061/A1050 and ADC12/A1050 FG Al foam specimens were 80-88\% and 75-84\%, respectively. The values of $d_{\mathrm{m}}$ for the A1050, A6061 and ADC12 uniform Al foam specimens were 1.8-2.4 mm, 1.9-2.5 $\mathrm{mm}$ and 1.1-1.3 mm, respectively. Those for the A6061/A1050 FG Al foam specimens were almost the same as those for the A6061 and A1050 layers and were 2.3-2.5 mm. Those for the ADC12/A1050 FG Al foam specimens were 1.3-1.5 $\mathrm{mm}$ in the ADC12 layer and 2.1-2.6 $\mathrm{mm}$ in the A1050 layer. As examples of the relationship between the distance $x$ from the top of a specimen, as shown in Figs. 2 and 4, normalized by the height $h$ of the specimen, and the local porosity $p_{x}$ on the cross sectional distance $x$ evaluated from X-ray CT images, Figs. 5(a) and (b) show the results 
for the A6061 uniform Al foam specimen with porosity $p=86.3 \%$ and the A6061/A1050 FG Al foam specimen with porosity $p=84.9 \%$ respectively.

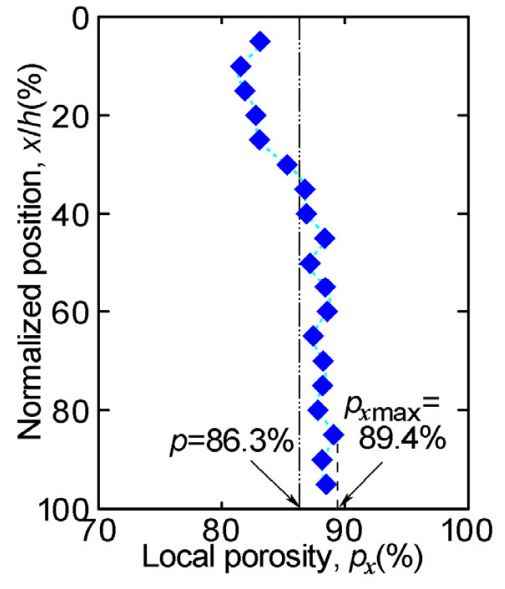

(a)

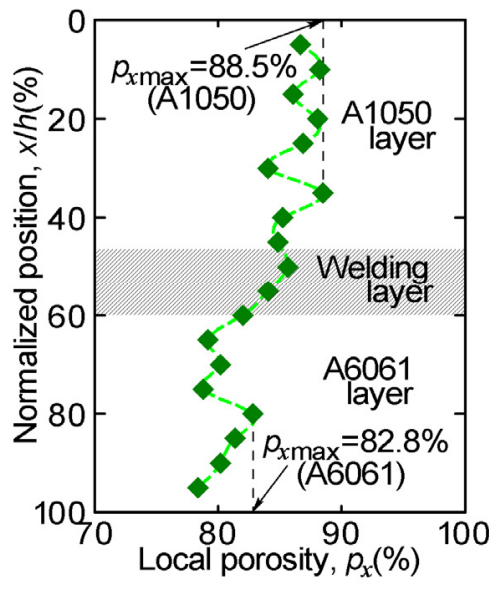

(b)

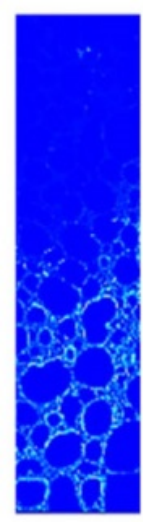

(c)

Fig. 5 Distribution of local porosity $p_{x}$ and distribution of elemental Mg evaluated by EPMA mapping analysis. (a) Distribution of $p_{x}$ of A6061 uniform Al foam specimen ( $p=86.3 \%$ ). (b) Distribution of $p_{x}$ and (c) distribution of elemental Mg of A6061/A1050 FG Al foam specimen ( $p=84.9 \%$ ) (Hangai et al., 2015).

\subsection{Microstructure observation}

For the obtained A6061/A1050 FG Al foam specimen, the distribution of elemental Mg, which only exists in A6061 Al alloy, on the surface of the specimen was observed using an electron probe microanalyzer (EPMA-1620, Shimadzu Corporation). To avoid damaging the specimen, instead of the cut surface of the specimen, the cut surface of a separate part was used. It was assumed that the distribution of elemental $\mathrm{Mg}$ on the cut surface was almost the same as that on the specimen surface. The observed surface was ground using SiC paper (of up to \#2400) and then polished with alumina $(1 \mu \mathrm{m})$ before the EPMA observation. In Fig. 5(c), distribution of elemental Mg evaluated by EPMA mapping analysis is shown. As the porosity and pore size differences of the two layers in the A6061/A1050 FG Al foam specimen were not particularly large, the stirring layer between the two layers was determined from the distributions of $p_{x}$ and elemental $\mathrm{Mg}$. These distributions of $p_{x}$, as shown in Fig. 5, were used to estimate the plateau stresses for the uniform $\mathrm{Al}$ foam specimens and each foam layer of the $\mathrm{FG} \mathrm{Al}$ foam specimens.

\section{Compression tests \\ 4.1 Test procedures}

Impact compression tests were carried out at room temperature in accordance with Japanese Industrial Standards JIS H7904 (Japanese Standards Association, 2012) using a drop weight impact testing system (Dynatup 9250HV, Instron). The weight velocity of impact onto the specimens was $4.4 \mathrm{~m} / \mathrm{s}$ under free fall from a height of $1 \mathrm{~m}$. Masses of $25.6 \mathrm{~kg}, 6.5 \mathrm{~kg}$ and $25.6 \mathrm{~kg}$ were used for the A6061/A1050 and ADC12/A1050 FG Al foam specimens, the A1050 uniform Al foam specimen and the A6061 and ADC12 uniform Al foam specimens, respectively. These masses were selected by consideration of the absorption energy up to the densification of the specimen that occurred in the static compression tests mentioned below. During the impact compression tests, sequential deformation images of the specimens were visually observed by a high-speed camera (FASTCAM-MAX120K, Photron). The frame rate and sampling rate were set to $6000 \mathrm{fps}$ and $1200 \mathrm{kHz}$, respectively.

Static compression tests on the specimens were also carried out at room temperature in accordance with Japanese Industrial Standards JIS H7902 (Japanese Standards Association, 2008) using universal testing machine (Autograph AG-100kNG, Shimadzu Corporation) at a strain rate of $3.3 \times 10^{-3} \mathrm{~s}^{-1}$. During the static compression tests, sequential deformation images of the specimens were visually observed by a video camera. 


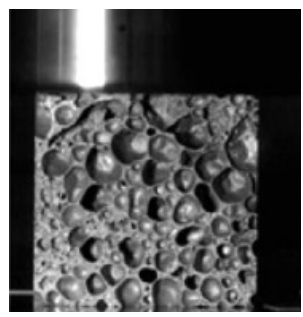

(a) initial

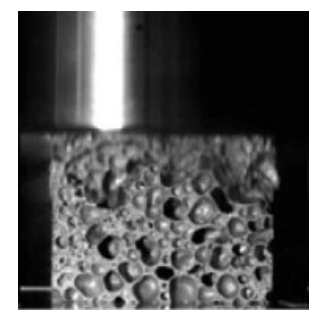

(b) $\varepsilon=0.2$

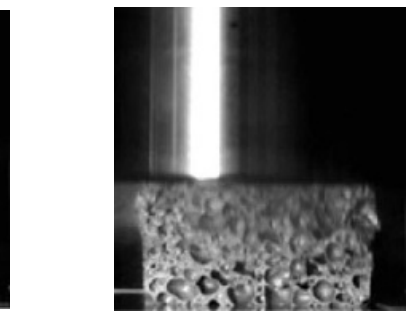

$10 \mathrm{~mm}$

(c) $\varepsilon=0.4$

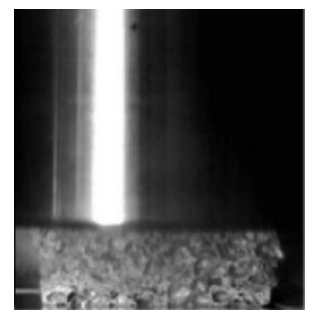

(d) $\varepsilon=0.6$

Fig. 6 Deformation images for different strains during impact tests on A6061 uniform Al foam specimen $(p=85.1 \%)$.

(a) Initial, (b) $\varepsilon=0.2$, (c) $\varepsilon=0.4$ and (d) $\varepsilon=0.6$ (Hangai et al., 2015).

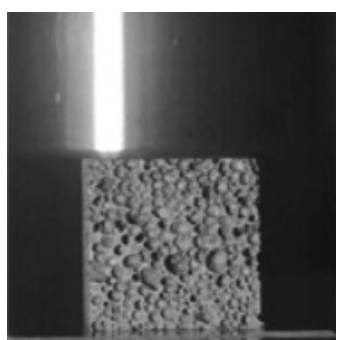

(a) initial

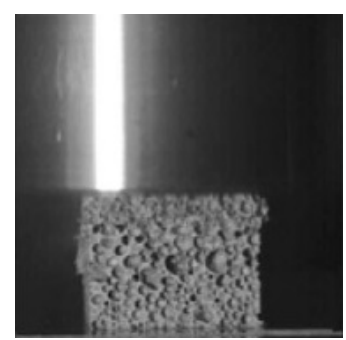

(b) $\varepsilon=0.2$

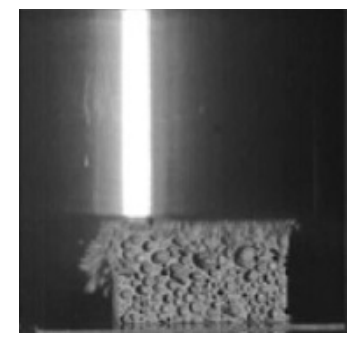

(c) $\varepsilon=0.4$

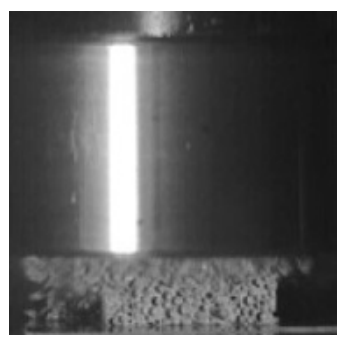

(d) $\varepsilon=0.6$

Fig. 7 Deformation images for different strains during impact tests on ADC12 uniform Al foam specimen $(p=80.3 \%)$.

(a) Initial, (b) $\varepsilon=0.2$, (c) $\varepsilon=0.4$ and (d) $\varepsilon=0.6$.

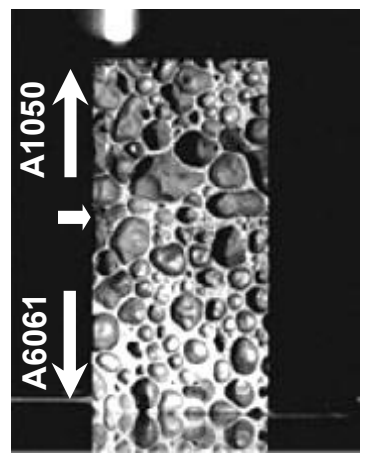

(a) initial

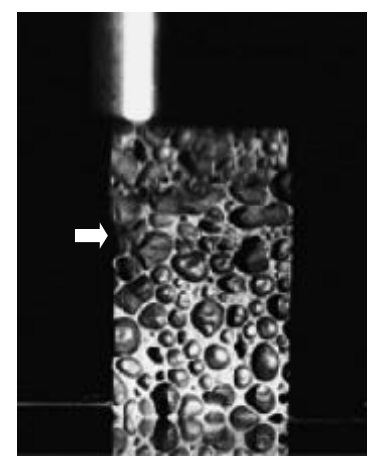

(b) $\varepsilon=0.2$

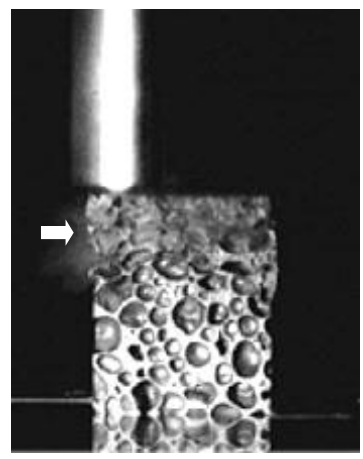

(c) $\varepsilon=0.4$

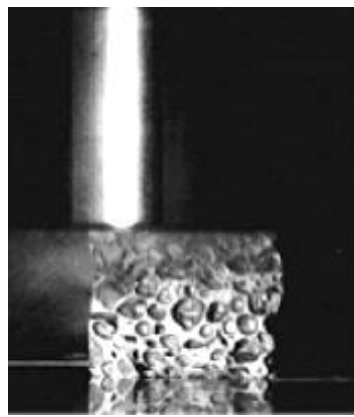

(d) $\varepsilon=0.6$

Fig. 8 Deformation images for different strains during impact tests on A6061/A1050 FG Al foam specimen $(p=84.9 \%)$. (a) Initial, (b) $\varepsilon=0.2$, (c) $\varepsilon=0.4$ and (d) $\varepsilon=0.6$ (Hangai et al., 2015).

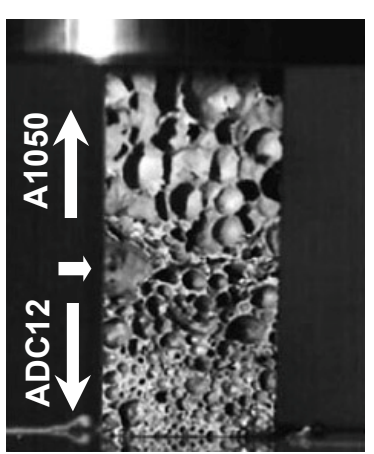

(a) initial

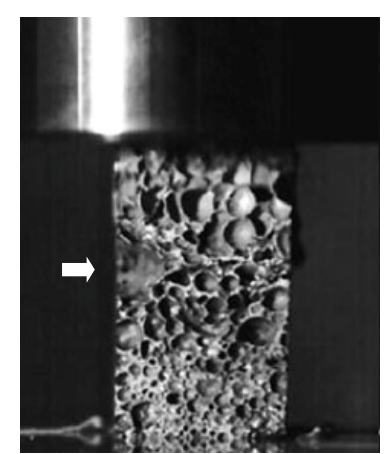

(b) $\varepsilon=0.2$

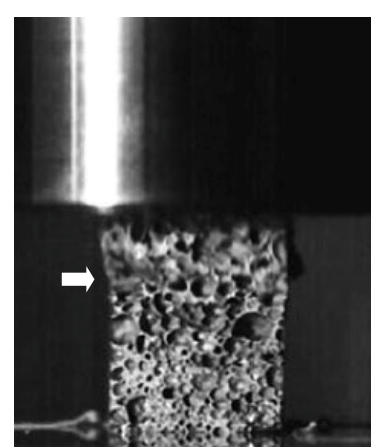

(c) $\varepsilon=0.4$

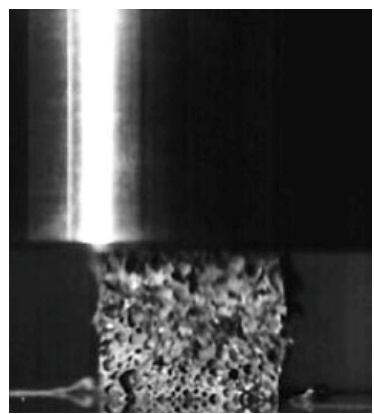

(d) $\varepsilon=0.6$

Fig. 9 Deformation images for different strains during impact tests on ADC12/A1050 FG Al foam specimen $(p=83.2 \%)$.

(a) Initial, (b) $\varepsilon=0.2$, (c) $\varepsilon=0.4$ and (d) $\varepsilon=0.6$. 


\subsection{Fracture states of specimens}

As examples of deformation images obtained in the impact compression tests, Figs. 6 and 7 show the results for the A6061 and ADC12 uniform Al foam specimens, respectively. Also, Figs. 8 and 9 show the results for the A6061/A1050 and ADC12/A1050 FG Al foam specimens, respectively. The white arrows in Figs. 8 and 9 indicate the initial boundary between the two foam layers in the A6061/A1050 and ADC12/A1050 FG Al foam specimens. The deformation states for all the uniform $\mathrm{Al}$ foam specimens and FG Al foam specimens were similar to those in previously reported impact tests (Hangai et al., 2015) and static compression tests (Utsunomiya et al., 2010b, Hangai et al., 2014). That is, the FG Al foam specimen first started to deform only in the weaker Al (A1050) foam layer and then deformed in the high-strength $\mathrm{Al}$ (A6061 or ADC12) foam layer. Also, as discussed in the previous studies (Hangai et al., 2015, Utsunomiya et al., 2013), it can be considered that substantial deformation started from the weaker layer with higher porosity and proceeded layer by layer in the uniform Al foam specimens and in each foam layer of the FG Al foam specimens. Moreover, during the static and impact compression tests on the A6061 and A1050 uniform Al foam specimens and the A6061/A1050 and ADC12/1050 FG Al foam specimens, the dropping and scattering of collapsed small fragments were hardly observed because ductile deformation occurred. On the other hand, for the ADC12 uniform Al foam specimen and the ADC12 Al foam layer of the ADC12/A1050 FG Al foam specimen, although collapsed small fragments gradually dropped from the specimens in the static compression tests owing to localized brittle fracture (Utsunomiya et al., 2010b, Hangai et al. 2012b), numerous small fragments were scattered instantly in the impact compression tests (Utsunomiya et al., 2014). It can be deduced from the scattering of the fragments that the plateau stresses for the ADC12 uniform $\mathrm{Al}$ foam specimen and the ADC12 Al foam layer of the ADC12/A1050 FG Al foam specimen in the impact compression tests are lower values than those in the static compression tests.

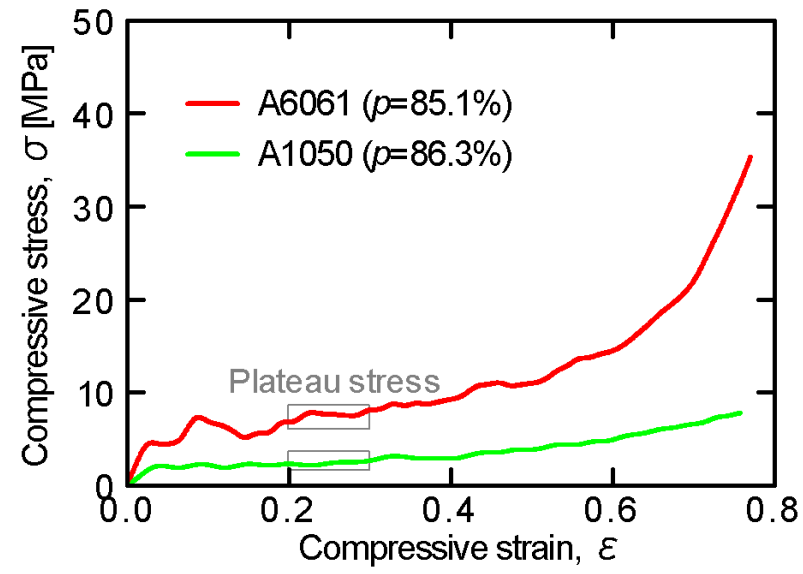

Fig. 10 Nominal stress-strain curves of uniform A6061 and $\mathrm{A} 1050$ uniform $\mathrm{Al}$ foam specimens obtained during the impact compression tests and range of strain at plateau stress (Hangai et al., 2015).

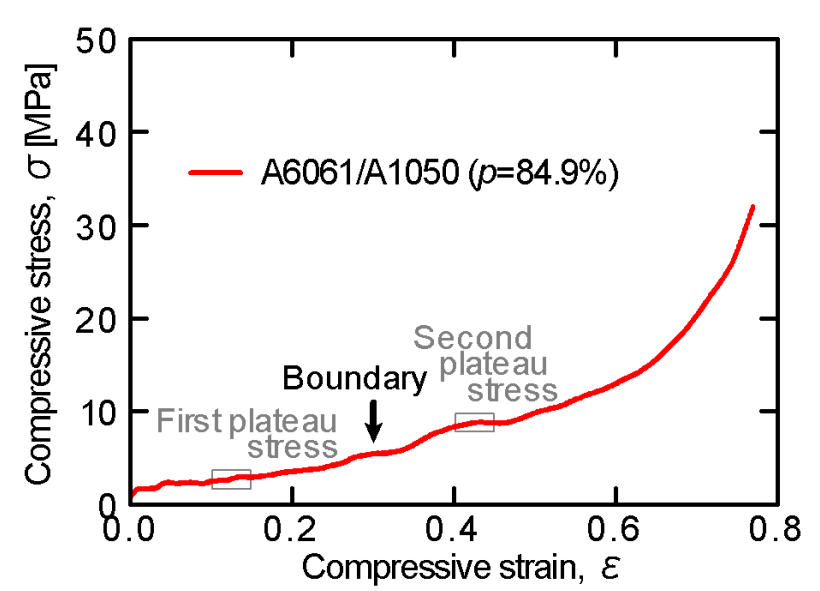

Fig. 11 Nominal stress-strain curves of A6061/A1050 FG $\mathrm{Al}$ foam specimen obtained during the impact compression test and ranges of strain at first and second plateau stresses (Hangai et al., 2015).

As examples of nominal stress-strain curves for the uniform Al foam specimens, Fig. 10 shows the results for the A6061 uniform Al foam specimen with porosity $p=85.1 \%$ and the A1050 uniform Al foam specimen with porosity $p=86.3 \%$ obtained during the impact compression tests (Hangai et al., 2015). In these figures, a plateau region with a nearly constant stress can be clearly observed, then the plateau stress was evaluated as the average stress for the range of strain of 0.2-0.3 in accordance with the Japanese Industrial Standards (Japanese Standards Association, 2008, 2012). As an example of a nominal stress-strain curve for an FG Al foam specimen, Fig. 11 shows the results for the A6061/A1050 FG Al foam specimen with porosity $p=84.9 \%$ during the impact compression test. By assuming that the deformations in the first and second plateau regions only occurred in the A1050 and A6061 Al foam layers, respectively, the first and second plateau regions, which corresponded to those appearing in each foam layer, can be defined independently for the FG Al foam specimens. In the first plateau region, we modified the nominal strain for the uniform $\mathrm{Al}$ foam specimen $\varepsilon_{\mathrm{Uni}}$ to that for the $\mathrm{FG} \mathrm{Al}$ foam specimen $\varepsilon_{\mathrm{FG}}$ using 


$$
\varepsilon_{\mathrm{FG}}=\varepsilon_{\mathrm{Uni}} \times \frac{h_{1}}{h_{0}},
$$

where $h_{0}$ is the total height of the FG Al foam specimen $(40 \mathrm{~mm})$ and $h_{1}$ is the height of the weaker $\mathrm{Al}$ (A1050) foam layer of the FG Al foam specimen (approximately $20 \mathrm{~mm}$ ). The plateau stress in the first plateau region was evaluated as the average stress for the range of strain of approximately $0.1-0.15$ in the nominal stress-strain curve for the FG Al foam specimen. In the second plateau region, $\varepsilon_{\text {Uni }}$ was modified to $\varepsilon_{\mathrm{FG}}$ using

$$
\varepsilon_{\mathrm{FG}}=\varepsilon_{\mathrm{Uni}} \times \frac{h_{2}}{h_{0}}+\varepsilon_{\mathrm{IniB}},
$$

where $h_{2}$ is the height of the high-strength $\mathrm{Al}$ (A6061 or ADC12) foam layer of the FG Al foam specimen (approximately $20 \mathrm{~mm}$ ) and $\varepsilon_{\text {IniB }}$ is the nominal strain at which the high-strength Al (A6061) foam layer started to deform (approximately 0.3) (Hangai et al., 2015). The arrow labeled "boundary" in this figure indicates the position of $\varepsilon_{\text {IniB }}$ in the A6061/A1050 FG Al foam specimen. The plateau stress in the second plateau region was evaluated as the average stress for the range of strain from approximately $\varepsilon_{\mathrm{IniB}}+0.1$ to $\varepsilon_{\mathrm{IniB}}+0.15$ in the nominal stress-strain curve.

\section{Estimation of plateau stress}

\subsection{Estimation method based on mean true compressive stress on a maximum-porosity cross section}

In a previous paper, by simply assuming that when the mean true compressive stress on a maximum-porosity cross section perpendicular to the direction of compressive loading $\sigma_{l \max }$ reaches the critical value $\sigma_{\mathrm{cr}}$, the nominal compressive stress becomes equal to the plateau stress $\sigma_{\mathrm{pl}}$, we proposed that $\sigma_{\mathrm{p} l}$ can be estimated by the following equation (Utsunomiya et al., 2013):

$$
\sigma_{\mathrm{pl}}=\sigma_{l \max }\left(1-p_{l \max }\right)=\sigma_{\mathrm{cr}}\left(1-p_{l \max }\right),
$$

where $p_{l \max }$ is the maximum local porosity on the cross section perpendicular to the direction of compressive loading. From the distributions of $p_{x}$, as shown in Figs. 5(a) and (b), $p_{\text {lmax }}$ can be obtained for all the compression test specimens. In the A6061/A1050 and ADC12/A1050 FG Al foam specimens, the values of $p_{\text {lmax }}$ for individual A6061, ADC12 and $\mathrm{A} 1050 \mathrm{Al}$ foam layers were obtained. As the values of $\sigma_{\mathrm{cr}}$, the $0.2 \%$ proof stress $\sigma_{\mathrm{p}}$ (The Japan Institute of Light Metals, 1991, Japan Die Casting Association, 2015) and the flow stress $\sigma_{\mathrm{fl}}$ (Electric Power Research Institute, 1989), which is the average value of $\sigma_{\mathrm{p}}$ and the tensile strength $\sigma_{\mathrm{u}}$ (The Japan Institute of Light Metals, 1991, Japan Die Casting Association, 2016), were employed. These critical values were adopted for convenience as the parameters related to plastic collapse. For the static compression test results for the A1050 and ADC12 uniform Al foam specimens, it was shown that $\sigma_{\mathrm{pl}}$ can be estimated within $\pm 20 \%$ error by this simple estimation method when $\sigma_{\mathrm{p}}$ is used as the critical value (Utsunomiya et al., 2013).

\subsection{Estimation results and discussions}

Figures 12 shows the results estimated by Eq. (4) (lines) and the test results of the plateau stress $\sigma_{\mathrm{pl}}$ for (a) the A6061 uniform Al foam specimens and the A6061 Al foam layers of the A6061/A1050 FG Al foam specimens and (b) the A1050 uniform Al foam specimens and the A1050 Al foam layers of the A6061/A1050 FG Al foam specimens. In these figures, as references, the results (lines) corresponding to $\pm 20 \%$ error for the estimated results of $\sigma_{\mathrm{p}}$ for A6061 and $\mathrm{A} 1050 \mathrm{Al}$ foams are also shown (cf. the lines of $0.8 \sigma_{\mathrm{p}}$ and $1.2 \sigma_{\mathrm{p}}$ in Fig. 12). From these figures, although both the impact and static test results had significant variations owing to the variation of the pore structures in the specimens, it was revealed that the results obtained from the impact and static compression tests were almost the same for both the Al foam specimens and the layers. Also, these results showed almost the same tendency for $\sigma_{\mathrm{pl}}$ to decrease with increasing $p_{l \max }$ and were mostly in the range of $\pm 20 \%$ of the estimated result for $\sigma_{\mathrm{p}}$. The estimated results for $\sigma_{\mathrm{fl}}$ closely corresponded to the maximum value in the test results.

Figures 13 shows the results estimated by Eq. (4) (lines) and the test results of $\sigma_{\mathrm{pl}}$ for (a) the ADC12 uniform Al foam specimens and the ADC12 Al foam layers of the ADC12/A1050 FG Al foam specimens and (b) the A1050 uniform $\mathrm{Al}$ foam specimens and the A1050 Al foam layers of the ADC12/A1050 FG Al foam specimens. In these figures, the lines of $0.8 \sigma_{\mathrm{p}}$ and $1.2 \sigma_{\mathrm{p}}$ for the $\mathrm{ADC} 12$ and $\mathrm{A} 1050 \mathrm{Al}$ foams are also shown. Also in these figures, both the impact and static test results had significant variations owing to the variation of the pore structures in the specimens. 
For the A1050 Al foam layers of the ADC12/A1050 FG Al foam specimens, as shown in Fig. 13(b), the test results for $\sigma_{\mathrm{pl}}$ are mostly within $\pm 20 \%$ of the estimated result for $\sigma_{\mathrm{p}}$, and the estimated results for $\sigma_{\mathrm{fl}}$ closely corresponded to the maximum value in the test results. This tendency of the A1050 Al foam is similar to that in Fig. 12(b). However, for the ADC12 Al foam specimen and the ADC12 Al foam layers of the ADC12/A1050 FG Al foam specimens, as shown in Fig. 13(a), it can be seen that although the static test results for $\sigma_{\mathrm{pl}}$ are mostly within $\pm 20 \%$ of the estimated result for $\sigma_{\mathrm{p}}$, the impact test results for $\sigma_{\mathrm{pl}}$ are approximately $20 \%$ lower than the estimated result for $\sigma_{\mathrm{p}}$. It is found that the estimated $\sigma_{\mathrm{p}}$ for the $\mathrm{ADC} 12 \mathrm{Al}$ foam closely corresponded to the maximum value obtained in the impact test. We consider that this tendency of the impact test results is mainly because the cross-sectional area was decreased by the instantaneous scattering of small collapsed fragments as mentioned in 4.2 section.

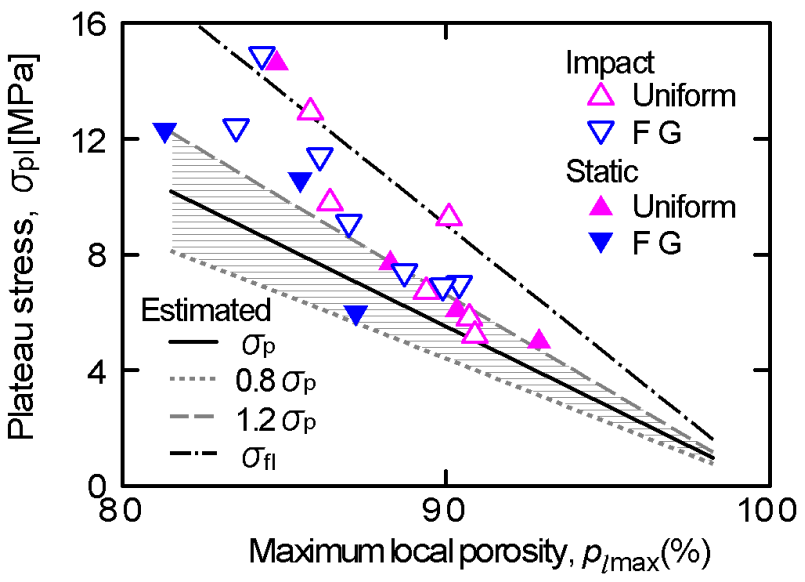

(a)

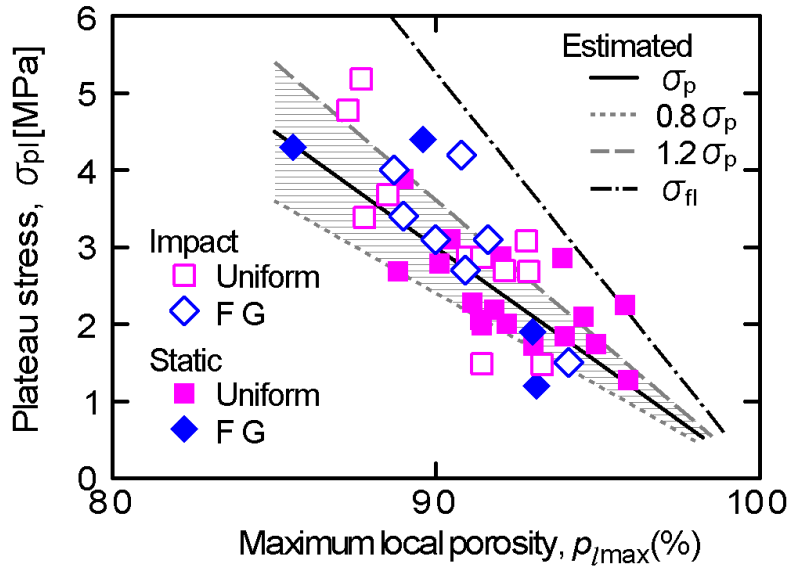

(b)

Fig. 12 Relationship between the estimated results and the experimental results for plateau stresses. (a) A6061 uniform Al foam specimens and A6061 Al foam layer of A6061/A1050 FG Al foam specimens. (b) A1050 uniform Al foam specimens and A1050 Al foam layer of A6061/A1050 FG Al foam specimens.

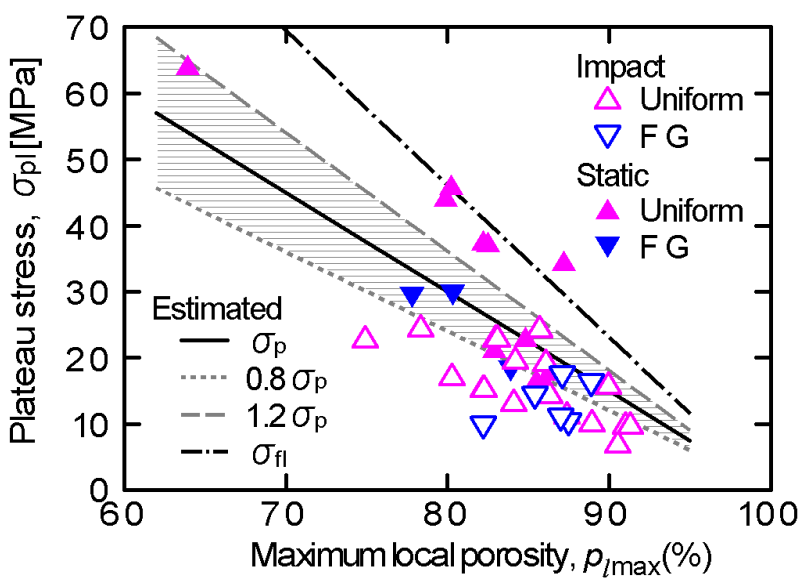

(a)

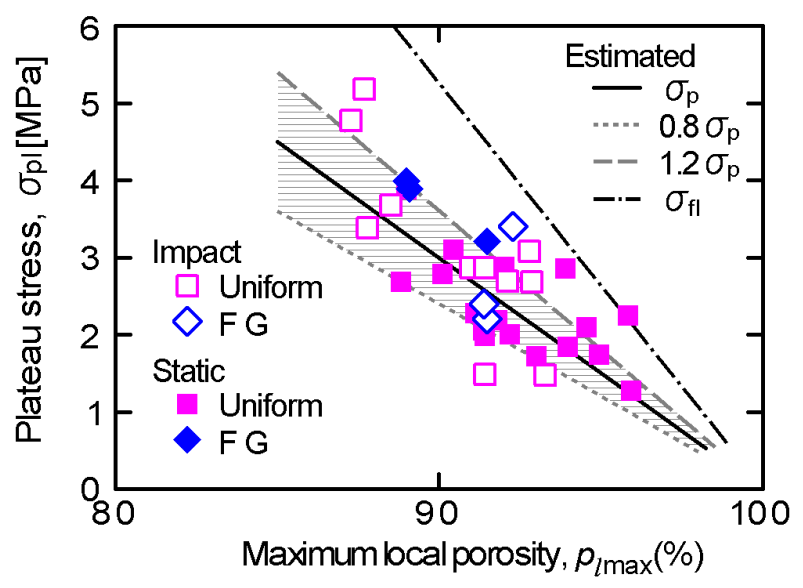

(b)

Fig. 13 Relationship between the estimated results and the experimental results for plateau stresses. (a) ADC12 uniform $\mathrm{Al}$ foam specimens and ADC12 Al foam layer of ADC12/A1050 FG Al foam specimens. (b) A1050 uniform Al foam specimens and $\mathrm{A} 1050 \mathrm{Al}$ foam layer of $\mathrm{ADC} 12 / \mathrm{A} 1050 \mathrm{FG} \mathrm{Al}$ foam specimens.

From these results, it was concluded that for the uniform $\mathrm{Al}$ foam specimens and the $\mathrm{Al}$ foam layers of $\mathrm{FG} \mathrm{Al}$ foam specimens, for which ductile deformation occurs, the plateau stress $\sigma_{\mathrm{pl}}$ can be estimated from the mean true compressive stress on a maximum-porosity cross section $\sigma_{l \max }$ when $\sigma_{\mathrm{p}}$ is used as the critical value. On the other hand, for the uniform $\mathrm{Al}$ foam specimens and the $\mathrm{Al}$ foam layers of $\mathrm{FG} \mathrm{Al}$ foam specimens, for which local brittle fracture occurs, the values of $\sigma_{\mathrm{p} l}$ obtained in the static compression test can be estimated within an error of $\pm 20 \%$ by the same estimation method. In the impact compression test, when numerous small fragments were scattered instantly, the test 
results for $\sigma_{\mathrm{pl}}$ were slightly lower than the results estimated by the same estimation method. Clearly, further extensive studies are necessary to improve the accuracy of this estimation method for the plateau stress by considering the effects of the pore structure and the fracture state, which were not discussed in this study.

\section{Conclusion}

In this study, uniform A1050, A6061 and ADC12 Al foams and A6061/A1050 and ADC12/A1050 FG Al foams were fabricated, and impact and static compression tests were carried out on their specimens. An estimation method for plateau stress based on the mean true compressive stress on a maximum-porosity cross section was applied to the test results and the accuracy of this method was evaluated. The results led to the following conclusions.

(1) From the X-ray CT observation and EPMA observation of the uniform Al foam specimens and FG Al foam specimens, the local porosity on a cross section perpendicular to a direction of compressive loading could be evaluated. From the distribution of local porosity, the maximum local porosity could also be obtained.

(2) Ductile deformation occurred in the static and impact compression tests on the A6061 and A1050 uniform Al foam specimens and the A6061 and A1050 Al foam layers of the A6061/A1050 and ADC12/1050 FG Al foam specimens, and the dropping and scattering of collapsed small fragments were hardly observed.

(3) In the static compression tests on the ADC12 uniform Al foam specimen and the ADC12 Al foam layer of the ADC12/A1050 FG Al foam specimens, small fragments gradually became detached from the specimen as a result of localized brittle fracture. In the impact compression tests, numerous small fragments were scattered instantly.

(4) In the impact and static compression tests on the A6061 and A1050 uniform Al foam specimens and the A6061 and A1050 Al foam layers of the FG Al foam specimens, which exhibited ductile deformation, the plateau stresses can be estimated within $\pm 20 \%$ error by the estimation method using the proof stress.

(5) In the impact compression tests on the ADC12 uniform Al foam specimen and the AD12 Al foam layer of the FG Al foam specimens, the test results for the plateau stress were approximately $20 \%$ lower than those estimated from the proof stress because fragments were scattered instantly by brittle fracture. In the static compression tests on the specimens, the plateau stresses can be estimated within $\pm 20 \%$ error by the estimation method using the proof stress.

\section{Acknowledgments}

This work was partly financially supported by the Light Metal Education Foundation, Inc. and the Amada Foundation. The authors thank Dr. Takeshi Takatoya, Japan Aerospace Exploration Agency (JAXA), for his invaluable support in conducting the impact compression tests.

\section{References}

Banhart, J., Aluminium foams for lighter vehicles. International Journal Vehicle Design,Vol. 37 (2005), pp. 114-125.

Banhart, J. and Seeliger, H. W., Recent Trends in Aluminum Foam Sandwich Technology, Advancesd Engineering Materials, Vol. 14 (2012) pp. 1082-1087.

Banhart, J., Light-Metal Foams - History of Innovation and Technological Challenges, Advanced Engineering Materials, Vol. 15 (2013), pp. 82-111.

Brothers, A. H. and Dunand, D. C., Mechanical properties of a density-graded replicated aluminum foam, Materials Science and Engineering A, Vol. 489 (2008), pp. 439-443.

Electric Power Research Institute, Ductile Fracture Handbook Volume 1 (1989), p. 3-1.

Gibson, L.J., Mechanical Behavior of Metallic Foams, Annual Reviews, Materials Science, Vol. 30 (2000), pp. 191227.

Hangai, Y., Ozeki, Y. and Utsunomiya, T., Forming Condition of Porous Aluminum in Fabrication of ADC12 Aluminum Alloy Die Castings by Friction Stir Processing, Materials Transactions, Vol. 50 (2009), pp. $2154-2159$.

Hangai, Y., Utsunomiya, T. and Hasegawa, M., Effect of Tool Rotating Rate on Forming Properties of Porous Aluminum Fabricated by Using Friction Stir Processing, Journal of Materials Processing Technology, Vol. 210 (2010), pp. 288-292.

Hangai, Y., Takahashi, K., Utsunomiya, T., Kitahara, S., Kuwazuru, O. and Yoshikawa, N., Fabrication of functionally 
graded aluminum foam using aluminum alloy die castings by friction stir processing, Materials Science and Engineering A, Vol. 534 (2012a), pp. 716-719.

Hangai, Y., Kato, H., Utsunomiya, T., Kitahara, S., Kuwazuru, O. and Yoshikawa, N., Effects of Porosity and Pore Structure on Compression Properties of Blowing-Agent-Free Aluminum Foams Fabricated from Aluminum Alloy Die Castings, Materials Transactions, Vol. 53 (2012b), pp. 1515- 1520.

Hangai, Y., Saito, K., Utsunomiya, T., Kitahara, S., Kuwazuru, O. and Yoshikawa, N., Compression Properties of Al/Al-Si-Cu Alloy Functionally Graded Aluminum Foam Fabricated by Friction Stir Processing Route, Materials Transactions, Vol. 54 (2013), pp. 405-408.

Hangai, Y., Saito, K., Utsunomiya, T., Kuwazuru, O. and Yoshikawa, N., Fabrication and compression properties of functionally graded foam with uniform pore structures consisting of dissimilar A1050 and A6061 aluminum alloys, Materials Science \& Engineering A, Vol. 613(2014), pp. 163-170.

Hangai, Y., Kubota, N., Utsunomiya, T., Kawashima, H., Kuwazuru, O. and Yoshikawa, N., Drop weight impact behavior of functionally graded aluminum foam consisting of A1050 and A6061 aluminum alloys, Materials Science \& Engineering A, Vol. 639 (2015), pp. 597-603.

Hassani, A., Habibolahzadeh, A. and Bafti, H. Production of graded aluminum foams via powder space holder technique, Materials \& Design, Vol. 40 (2012), pp. 510-515.

Japan Die Casting Association, Die Casting, <http://www.diecasting.or.jp/diecast/pdf/book/pdf_set023-0. pdf >, pp. 19-20, (accessed on 25 December, 2015).

Japanese Standards Association, JIS-H-7902, Method for compressive test for porous and cellular metals (2008).

Japanese Standards Association, JIS-H-7904, High speed compression test for porous and cellular metals (2012).

Shinagawa, K., Shape change and pore distribution in aluminum powder compacts by graded foaming, in: Lefebvre, L. P., Banhart, J. and Dunand, D. C. (Eds.), Porous Metals and Metallic Foams, DEStech Publications Inc., Lancaster (2008), pp. 95-98.

Suzuki, R. and Kitazono, K., Effect of graded pore distribution on thermal insulation of metal foam., Journal of the Institute of Metals and Materials, Vol. 72 (2008), pp. 758-762 (in Japanese).

The Japan Institute of Light Metals, Microstructures and Properties of Aluminum (1991), p. 415.

Utsunomiya, T., Tamura, K., Hangai, Y., Kuwazuru, O. and Yoshikawa, N., Effects of Tool Rotating Rate and Pass Number on Pore Structure of A6061 Porous Aluminum Fabricated by Using Friction Stir Processing, Materials Transactions, Vol. 51 (2010a), pp. 542-547.

Utsunomiya, T., Takahashi, K., Hangai, Y., Kawano, S., Kuwazuru, O. and Yoshikawa N., Pore structure and compressive properties of $\mathrm{ADC} 12$ porous aluminum fabricated by friction stir processing route, Journal of the Japan Society of Light Metals, Vol. 60 (2010b), pp. 590-595 (in Japanese).

Utsunomiya, T., Takahashi, K., Hangai, Y. and Kitahara, S., Effects of Amounts of Blowing Agent and Contained Gases on Porosity and Pore Structure of Porous Aluminum Fabricated from Aluminum Alloy Die Casting by Friction Stir Processing Route, Materials Transactions, Vol. 52 (2011), pp. 1263-1268.

Utsunomiya, T., Yamaguchi, R., Hangai, Y., Kuwazuru, O. and Yoshikawa, N., Estimation of Plateau Stress of Porous Aluminum Based on Mean Stress on Maximum-Porosity Cross Section, Materials Transactions, Vol. 54 (2013), pp. 1182-1186.

Utsunomiya, T., Kubota, N., Hangai, Y., Ishima, T., Kawashima, H., Kuwazuru, O. and Yoshikawa, N., High-Speed Compressive Properties of Porous Material Fabricated Using Aluminum Alloy Die Casting JIS ADC12, Journal of the Japan Foundry Engineering Society, Vol. 86 (2014), pp. 840-845 (in Japanese). 